\title{
Translasyonel Araştırma Kavramı ve Okul Hemşireliği
}

\author{
Huri YOĞURTCU *, Fatma Şeyda ÖZBIÇAKÇI **
}

Öz

Translasyonellik kavramı araştırmalar ile elde edilmiş bilimsel bilgilerin teori statüsünden çıkartılarak uygulamaya dönüştürülmesi için yapılan tüm iş ve işlemlerin bileşkesiolarak açıklanır. Literatür bilgileri ile uygulama alanlarında kullanılan bilgiler kıyaslandığında kanıtların istenilen düzeyde uygulamaya dönüştürülemediği açıktır. Oysa teori düzeyinde kalmış her bilgi boşa giden iş gücü, finnans ve etkisiz bilgi yönetimi anlamı taşır. Okul hemşireliği kanıtların ve translasyonel araştırmaların üst düzeyde kullanımını gerektirir. Bu derlemenin amacı translasyonel araştırma konusunda bilgi kaynağı oluşturmak, meslek üyelerinde farkındalık geliştirmek, bilimsel bilgilerin okul sağlığı hemşireliği ve diğer uygulama alanlarına entegrasyonuna katkı sağlamaktır.

Anahtar kelimeler: Translasyonel Araştırma, Hemşirelik, Okul Hemşireliği, Elektronik Kayıtlar

\begin{abstract}
The Concept of TranslationalResearchand School Nursing

The concept of translationality is the result of all the Works and processes that are taken from the theory status of the scientific in formation obtained through research and converted in to practice. Clearly, when the information used in the literature and the application fields is compared, the evidence cannot be converted into practice at the desired level. However, every information that has remained at the level of theory means wasted workforce, finance and ineffective information management. School health nursing requires a high level of use of evidence and translational research. School nursing requires a high level of use of evidence and translational research. The aim of this review is to create a source of information on translational research, to raise awareness of the members of the profession, to contribute to the integration of scientific knowledge to school health nursing and other fields of practice.
\end{abstract}

Key Words: Translational Research, Nursing, School Nursing, Electronic Records

Geliş tarihi: 22.05.2020 Kabul tarihi: 03.03.2021

$\mathrm{T}$ Translasyonel Araşıırma(TA); kanıt temelli girişimlerin uygulama alanlarında kullanılabilirliğini/uygulanabilirliğini bireysel ve kurumsal düzeyde saptamaya/ ölçmeye/ anlamaya çalışan bilimsel bir yaklaşımdır(1).Günlük uygulamalarda yaygın ve efektif olarak kullanılabilen klinik veya toplumsal çalışmalardan genelleştirilebilecek fikir kavram ve keşiflerden tasarlanabilen aktivitelerdir (2).TA teorik düzeyde, kendine özgü, karmaşık olan araştırma sonuçlarının uygulamaya dönüştürülerek bir dinamizm kazandırılması, klinikte/sahada kullanımını sağlayarak verim elde edilmesine katkıda bulunur (1).Kliniklerde yapılan iş ve işlemlerin farklı disiplinleri temsil eden profesyonellerden oluşturulmuş bir ekip tarafından gerçekleştirildiğinden yola çıkarak, TA'nın etkili olmasında iletişim ve iş birliğinin en üst düzeyde sağlanması büyük önem taşır. Bunun yanı sıra TA'da süreç ve sonuca odaklanılması, çıkış noktasının henüz teorik düzeydeki bilgiler olması, multidisipliner ilişkiler yerine interdisipliner ilişkilerin tercih edilmesi diğer önemli parametrelerdir. TA'ların içeriği çok zengindir, sanki sadece klinik odaklılığa dikkati çekiyor gibidir ancak; evde bakım ve toplumların doğal yaşam ortamlarına odaklandığı da göz ardı edilemez (3-6). Hemşirelikte Translasyonel Araştırma (HTA) kavramı diğer temel bilimler ile benzer amaçlar içerir. HTA mevcut hemşirelik uygulamalarını geliştirmeye, yeni bilgiler ve uygulamalar elde etmeye, kanıtları güçlendirmeye, kanıt temelli ve nitelikli bakım girişimlerine katkı sağlamaya odaklanır. Bilim ve teknolojinin ilerlemesi, yaşam süresinin uzaması, evde bakım hizmetlerinin yaygınlaşması, bireylerin ve toplumların bilinçlenmesi sonucu sağlık bakım sürecine katılma gereksiniminin ortaya çıkması, beklentilerin artması HTA'ları önemli bir gereklilik haline getirmiştir (7). TA kavramı kırk yılı aşkın bir süredir literatürde var olmasına rağmen (7), henüz istenilen düzeyde anlaşılamamıştır (1). Bunun nedenleri arasında finansal sorunlar yer alsa da daha da önemlisi bilim insanlarında TA kültürünün tam anlamıyla benimsenmediği ve geleneksel yöntemleri bırakmak istememeleri göze çarpmaktadır. TA'nın profesyonelce yapılması bilgi, deneyim, interdisipliner uyum, özveri, zaman ve şeffaflık gerektirir. Bu bağlamda TA sonucunda ortaya çıkacak işin kalitesi, niteliği, faydaları bilim insanlarında bir bilinmezlik endişesi yaratmaktadır $(1,7,8)$. Endişelerin nedenlerinden biri de şüphesiz, TA'nın kapsamının son beş yıl gibi kısa bir zaman önce net olarak tanımlanmış olmasıdır (3-6). Araştırmacıların ve bilim insanlarının TA'ya olan inancının artırılması, mevcut endişelerin giderilmesi, konuya gereken ilginin gösterilmesinde liderlere gereksinim duyulmaktadır (7, 9). Translasyonel bilimine derinlemesine dalmak, yöntemlerin araştırılması, girişimler ve bireyler tarafından kanıta dayalı uygulamaların benimsenmesi başarı oranını arttıracaktır (7).

Okul hemşireliği ve translasyonel araştırma kavramı ile ilgilenen araştırmacıların alandaki konular üzerinde birleşmeleri, lider davranmaları, bilgi ve becerilerini bu alanda kullanmaları gelişim odaklı davranmalarına olanak tanıyacaktır (10). Bunun için mevcut elektronik sağlık kayıtlarının incelenmesi, bilgi bankalarından verilerin dökümante edilerek gerekli çıkarımların yapılması, klinisyenlerle iş birliği yapılarak kronik hastalığı olan ve risk taşıyan öğrencilere ulaşımın sağlanması okulhemşireliği ve translasyonel araştırmaların daha birçok noktada kesişmesine olanak tanıyacaktır $(10,11)$. Paylaşılabilir ve karşılaştırılabilir okul hemşireliği verilerinin sağlık hizmetine dönüştürülebilmesi için translasyonel araştırma ve uygulamayı destekleyen ulusal eylem planları geliştirilmelidir $(7,11)$. Bu bağlamda okul hemşireliği için geniş veri setlerinin araştırmaya açık olduğu konusunda literatürdegeniş bir kabul vardır (11).

* Dokuz Eylül Üniversitesi Sağlık Bilimleri Enstitüsü, Halk Sağlığı Hemşireliği Anabilim Dalı Doktora öğrencisi, 35340, İnciraltı/İzmir. eposta:huri.yogurtcu@gmail.com, ORCID: 0000-0001-9516-0581, ** Doç. Dr. Dokuz Eylül Üniversitesi Hemşirelik Fakültesi Halk Sağlığı Hemşireliği Anabilim Dalı, İzmir. ORCID: 0000-0001-6051-946X 
Derleme

Bu derleme; Translasyonel Araştırma kavramını irdelemek, hemşirelik bilimi için öneminin anlaşılması ve araştırmacılar için bir bilgi kaynağı oluşturmak, araştırmalar ile elde edilmiş kanıtların başta okul hemşireliği olmak üzere diğer uygulama alanlarına dönüştürülme sürecine katkı sağlamak amacıyla hazırlandı.

\section{Translasyonel araştırmaların önemi ve işleyişi}

TA elde edilmiş kanıtların günlük sağlık bakımı uygulamalarına profesyonel düzeyde dönüşümünü amaçlar (12). Tanı, tedavi ve bakım uygulamalarının gelişimini destekleyen her türlü bilgi, uygulamaya dönüştürülemediği takdirde, literatürde yoğunluk ve bazen de kirlilik yaratmaktan daha ileriye gidemez. Ne var ki son y1llarda elde edilmiş yeni bilgilerin sadece \%14'ü uygulamaya entegre edilebilmiştir (13). Bu durum bilimsel bilgi ile insan faktörü arasında bir perde oluşturur ve bilim insanlarının iş gücü ve araştırma bütçelerinin yitip gittiği anlamını taşır. Bu bakımdan translasyonel araştırmalara ödenek ayrılarak hayata geçirilmesi, bilimsel bilginin etkili kullanımında önemli bir aşamayı oluşturur. Bilim insanlarının TA kavramının yeni şekillenmiş bir kavram olmasına yönelik taşıdığı endişeler, bilimsel bilgilerin istenilen düzeyde kullanılamıyor olması noktasında kaybolmalıdır. Uygulamaya dönüştürülmeyen bilgilerin insanlığa hiçbir faydası olmadan zamanla eskimesi bilimin yozlaşmasına neden olur. Oysa translasyonel araştırmalar bilimsel bilgiler ile insan faktörü arasında bir köprüdür, yeni bilgilerin uygulayıcılara ulaştırılmasını sağlar (14). Araştırma yöntemlerinin çok güçlü olması ve denemede kalmadan günlük pratiklere yansıması gereken hemşirelik mesleği, translasyonel araştırmaların istenilen düzeyde uygulanmamasından dolayı zarar görmektedir (14). Literatürde mevcut olan ancak uygulamada yer edinemeyen bilgiler etik ve yasal sorunları beraberinde getirir, mesleğin gücünü zayıflatır, profesyonelliği tehdit eder (15). TA’nın uygulamasında öneminin anlaşılmasının yanı sıra işleyiş̧i çok iyi bilinmelidir. Bu bağlamda TA beş aşamada uygulanır. Bu aşamalar;

1)T0: Öngörü oluşturma

2)T1: Yöntem geliştirme

3)T2: Girişimlerin/kanıtların etkinliğini ölçen küçük denemeler yapılması

4)T3: Girişimlerin/kanıtların etkinliğinin kapsamlı ölçümü

5) T4: Yararlılığı kanıtlanmış sonuçların yaygınlaştırılmasıdır (15).

TA'lar hakkındaki bilgi ve deneyim eksikliği nedeniyle araştırmacıların birçoğunun TR1 ve TR2 aşamalarına odaklandığı tahmin edilmektedir, ancak TR3 aşamasına geçilmediği takdirde yararlılıktan söz edilemez. T3 aşaması rehberlerin geliştirildiği, meta analiz ve sistematik incelemelerin yapıldığ için araştırmacı eğitimleri arttırılmalıdır (15). Disiplinler arasıilişkilerin önem kazandığı aşamadır. Transdisipliner ilişki; bilgi alışverişi, bilimsel yaklaşımların değiş-tokuşu, farklı disiplinlerden bilim insanlarının fikirlerinin ve yaklaşımlarının bütünleştirilmesi ile ortak bir bilimsel hedefe yönelik araştırmaların geliştirildiği, ortak projelerin oluşturulmasıdır. Transdisipliner ilişki profesyonellerin temel ve klinik geçmişlerinden gelen, uzmanlıklarını, deneyimlerini kullanarak ve farklı bakış açıları ile yaklaşımları bir araya getirerek birtakım olmalarını sağlar, temel bilimsel uygulamaların genel uygulamalara dönüşümünü gerçekleştirir $(14,16)$.

\section{Translasyonel araştırmaların bakım sürecinde kullanımı}

Hemşireler, son kırk yıldır araştırmalar ile elde edilmiş sonuçları, uygulama alanlarında istikrarlı bir şekilde kullanmakta ve önemli başarılar elde etmektedir (7). Kanıta dayalı hemşirelik girişimleri üzerine birçok kitap/yayın bulunmaktadır. Hemşirelik; teknolojik gelişmelerle ilerlemesi hız kazanmış, dünya nüfusunun yaşlanması ile birlikte önemli değişikliklere uğramış, heyecan verici, sürekli gelişen, çok kültürlü toplum yapısına uyum sağlamaya çalışan, değişime açık bir sağlık bilimidir. Tıp biliminin gelişimi, hasta güvenliği konusunda artan farkındalık, şeffaflık ve sağlık bakımının denetlenebilirliği konusunda kamu beklentileri hemşireliğin daha çok gelişmesi konusunda talep oluşturmaktadır. Hemşirelerin TA sürecine entegrasyon sağlamak, iş birliği yapmak, uzmanlığın geliştirilmesine destek olmak, yararlılığın artırılması, liderler tarafından kritik konuların tartışılması ve yönlendirmelerin yapılması, yeni bulguların uygulamaya dönüşümü ve gündeme getirilmesi konusunda efor sarf etmek gibi görevleri vardır. Ayrıca hastalık, öz-bakım, kronik hastalık, yaşam sonu bakım ve tedaviye uyum alanlarına güçlü ve tutarlı bir katkı sağlamak için hemşireler lider davranmalıdır (7, 10). Semptom yönetimi, kronik hastalık bakımında teknolojinin kullanımı, hastaların karmaşı diyetlerini yönetmelerine yardımcı olacak strateji geliştirmek konularında öncülük edilmelidir. Sağlığı geliştirme, riskleri önleme ve bilginin öz-bakıma entegrasyonu hemşirelik literatüründe daha fazla yer almalıdır. Sağlık bakım kuruluşları, üniversiteler, enstitüler, evde bakım hizmetleri translasyonel hemşirelik üzerine yoğunlaşmalıdır. Evde bakım hizmetleri translasyonel hemşirelik için öncelikli bir çalışma alanıdır. Uzun süreli bakım evlerinde yapılan bir çalışmada, translasyonel araştırmaların uygulamada kullanılması ile ağrı yönetiminde iyileşme sağlandığı belirtilmiştir (17). Translasyonel araştırma sonuçlarının klinik uygulamalar ile bütünleşmesi daha şeffaf ve sürdürülebilir bir sağlık bakım hizmeti sunmada fark yaratmak için önem taşımaktadır (18). Yine hemşirelerin sağlık eşitsizliklerini ele alma konusundaki deneyimleri dikkate alındığında translasyonel araştırmalar konusunda liderlik yapmaya daha fazla eğilimli olmalıdırlar. Hemşireliğin TA’ya yoğunlaşması, liderliğinin desteklenmesi, kanıtlara erişimi ve anlaşılması için koşullar idealize edilmeli, kurumlarda iş organizasyonu buna göre sağlanmalıdır $(19,20)$.

Translasyonel araştırma basamaklarının toplum, okul vb. ortamlarında ve klinik ortamlarda etkin kullanılabilmesi için bu alanlarda uygulanan çalışmalara hız verilmesi gereklidir. Literatürdeki çalışma sonuçlarına göre, okul hemşiresinin öğrencilerin büyüme ve gelişmelerinin izlenmesinde, sağlık durumları ve olası sağlık risklerinin tanılanmasında, akademik başarılarının artırılmasında önemli etkileri olduğu görülmüştür (21, 22). Ancak ülkemizde okul sağlığı hizmetlerinde okul hemşiresinin görev, yetki ve sorumlulukları hemşirelik yönetmelikleri ile belirlenmiş olmasına rağmen, kamuya ait okullarda okul hemşiresi istihdam edilmemektedir. Özel okulların bir kısmında okul hemşiresi istihdam edilmekte, ilk yardım uygulamaları ve hekim istem ile ilaç vermektedir $(22,23)$. Elektronik kayıtlar ve hemşirelik girişimlerine ilişkin süreçler henüz yaşama geçirilememiştir. Bu nedenle ülkemizde okul sağlığında görev alan okul hemşirelerinin translasyonel araştırmalar ile 
Derleme

ilgili yeterli bilgi ve farkındalıklarının olduğu söylenemez. Aynı zamanda bu kavram klinik alandaki hemşireler için de yeniliğini korumaktadır.

\section{Okul Hemşireliği ve Translasyonel Araştırmalar}

Translasyonel araştırmaların uygulamaya dönüşümünü kolaylaştırmada dört anahtar konu dikkat çeker, bunlar; erişilebilirlik, kalite, girişim güvenliği ve verimliliktir. Bu bağlamda bütçe planlamasının iyi yapılması göz ardı edilemez. Böylece etkin sağlık bakımı, iyi planlanmış teknoloji ve maliyet analizinin ayrılmaz bir bütün olduğu gerçeği ortaya çıkar. Tüm bunların gerçekleşmesi ve mevcut durumun saptanabilmesi için elektronik sağlık kayıtları eksiksiz, düzenli ve ivedilikle tutulmalı, istenilen zamanda dökümante edilebilmelidir (11). Elektronik sağlık kayıtlarının etkinliğinin en fazla olduğu çalışma alanlarından biri okul hemşireliği'dir. Bu elektronik sağlık kayıtlarının büyük bir bölümünü okul hemşireliği verileri oluşturmaktadır. $\mathrm{Bu}$ veriler translasyonel bilimi canlandırır $(11,24)$. Okul hemşireliği öğrencilerin mevcut akut ve kronik sorunlarını tanımlayan, periyodik olarak sağlık taramaları yapan, sağlık bakımı konularında öğrenci eğitimlerini üstlenen, okul saatleri içinde hemşirelik biliminin standartları çerçevesinde bakım sunmaya yetkili disiplindir (24). Translasyonel araştırma kavramı ile okul hemşireliği kalite, güvenli bakım, sürekli öğrenmeye hazıroluşluk noktalarında kesişirler (10, 25). Okul hemşireliği ve translasyonel araştırma kavramı ile ilgilenen araştırmacıların alanda birleşmeleri, lider davranmaları, bilgi ve becerilerini kullanmaları gelişim odaklı davranmalarına olanak tanıyacaktır. Bunun için mevcut elektronik sağlık kayıtlarının incelenmesi, bilgi bankalarından verilerin dökümante edilerek gerekli çıkarımların yapılması, klinisyenlerle iş birliği yapılarak kronik hastalığı olan ve risk taşıyan öğrencilere ulaşımın sağlanması okulhemşireliği ve translasyonel araştırmaların daha birçok noktada kesişmesine olanak tanıyacaktır (10). Okulhemşireleri rolleri gereği transdisipliner ilişki içerisinde olduğu için translasyonel araştırmalar yapmaya eğilimlidirler. Etkili bir okulhemşiresi elektronik sağlık kayıtları verilerini hızlı bir şekilde oluşturması ve bu verilerin okul sağlığı veri depolarına entegrasyonu ile verilerin translasyonel araştırmalarda ve kanıt temelli uygulamalarda kullanımını sağlayabilir (11). Çünkü elektronik kayıtlar sağlık bakımının okul yöneticileri, öğrenci velileri ve devlet yetkilileri tarafından takip edilmesine olanak tanır (26). Aynı zamanda elektronik sağlık kayıtlarında standartlaşmış okulhemşirelik girişimlerini uygulamak için de çeşitli aktiviteler vardır (11). Bu aktiviteler disiplin ve bireylere sorgulama olanağı sunar. Böylece problemin ne olduğu, neden kaynaklandığı, nasıl çözüldüğü ve niçin çözülemediği sorgulanır. Dolayısı ile kanıta dayalı uygulama, optimal sağlık bakımı sağlamada anahtar rol üstlenir (26). Kanıta dayalı uygulamaların ve translasyonel araştırmaların ortak özelliği elde edilen bilgilerin klinikte ve okul sağlığı ortamında kullanımını gerektirmesidir (27). Kanıta dayalı uygulamaların ve translasyonel araştırmaların okul sağlı̆̆ ortamında kullanımı, kaliteyi en üst düzeye çıkarma, maliyeti düşürme, hataları önleme, okul sağlığı kayıtlarının diğer bakım ortamlarındaki sağlayıcılarla birlikte çalışabilirliğini artırma potansiyeli vardır (28). Ancak ülkemizde riskli bölgelerden başlayarak bütün okullara bir okul hemşiresi ataması çağrıları yapılmasına rağmen, halen birçok okulda okul hemşiresi bulunmamaktadır (29). Ülkemizde okul sağlığ 1 ortamlarında elektronik sağlık kayıtlarının her kurumda standart olarak bulunmadığ1 ve hemşirelik literatüründe bu alanda boşluk olduğu söylenebilir. Okul çağı çocuklarında kronik hastalıkların görülme sıklığı oldukça yüksektir (26). Okulda iyi bir sağlık bakımı alamayan çocukların akademik etkinliklerde başarı oranı düşer, kronik hastalığı olanlar akranlarından geri kalır, büyüme ve gelişmesi olumsuz etkilenir (26). Literatür incelemelerinde kanıt temelli rehberler ile sunulan okul sağlığı bakım uygulamaları sonucunda çocuklarda fiziksel aktivitede artış gerçekleşmiş, sedanter davranışlarda azalma saptanmıştır (30).

Adams ve Carthy (2005), okul hemşirelerine, hemşire liderler ve hemşire araştırıcılarla birlikte çalışıp uygulamalarına ilişkin kanıta dayalı rehberler geliştirebilmek için translasyonel araştırmaları önermiştir (31). Dünyada okul sağlığı alanındaki translasyonel araştırmalar incelendiğinde; "çocukluk çağı obezite programının uygulamaya geçirilmesi ve etkinliğinin ölçülmesi” isimliçalışmadageliştirilen program yedi ülkede uygulanmış ve çocukluk çağında kilo kontrolü sağlama ve kilo vermede etkili olduğunu saptanmıştır. Bu programın uygulamaya geçirilmesi translasyonel araştırma modelinin T2 ve T3 aşamalarını kapsamaktadır (32).

Okul öncesi çocuklarda yaralanmaların azaltması amacıyla yapılan bir diğer translasyonel araştırma sonucu geliştirilen sekiz dakikalık bir animasyon filminin çocuklarda yaralanmaları azaltan yenilikçi bir girişim olduğu ifade edilmiştir, bu çalışma da T2 ve T3 aşamalarını kapsamaktadır (33). Hemşirelik "sağlığın geliştirilmesi ve korunması" üzerine odaklanmaktadır (34). Bu odaklanmadan hareketle Woods ve Magyary (2010) hemşirelikte translasyonel araştırmada iş birliğinin önemini vurgulamıştır (7). McClune ve Conway (2016) planladıkları translasyonel araştırmalarında okul hemşiresi olarak kullanılan dilin okul öncesi çocuklar için uygun olduğundan emin olmak için erken çocukluk eğitiminden bir öğretim üyesi, animasyon öğrencileri, müzisyen, kameraman ve tiyatro oyuncuları ile iş birliği içerisinde çalışmıştır. Projede her üyenin bir görevi vardı ve okul hemşireleri sağlı̆̆ın geliştirilmesinde gerekli konuların planlanması ile entegrasyonunda görev almıştır. Bu araştırma Woods ve Magyary'nin (2010) translasyonel araştırma modelinin T2 ve T3 aşaması temel alınarak gerçekleştirilmiştir (33).

Baldwin ve ark.'nın (2017) yaptığı diğer örnek araştırmada, sağlık eğitiminde farklı disiplinlerle çalışarak translasyonel araştırma sonuçlarının kullanımının öğrencilerde davranış değişikliği gerçekleştirdiği, okul ile toplum arasındaki bağı güçlendirdiği, bilginin uygulamaya dönüştürülmesini kolaylaştırdığı sonucuna ulaşılmıştır. Araştırma translasyonel araştırma modelinin T3 aşaması ile uyumludur (35).

Trivellini ve ark.'nın (2018), ergenlerdeki yaşam tarzı alışkanlıklarını, sosyal bağlamı, duygusal durumu ve zihinsel becerilerini bütünleşik bir refah endeksi ile değerlendirmek için yeni bir Web tabanlı araç geliştirmek amacıyla yaptıkları araştırmada; yaşam tarzı, sosyal, duygusal durum ve zihinsel beceri parametrelerinin platform aracılığıyla izlenmesi ile her bir parametrenin refah endeksi tanımlamasındaki rolünün belirlenmesine ve böylece önleyici ve kişiselleştirilmiş girişimsel stratejiler oluşturulmasına katkı sağlayacağı tespit edilmiştir. Araştırma translasyonel araştırma modelinin T3 aşaması ile uyumludur (36). 
Derleme

Chabot ve ark. 'nın (2010), okul hemşirelerinin öğrencilerin sağlığının geliştirilmesinde yeni tanımlanmış rolleri üstlenme niyetlerinin belirleyicilerinin araştırıldığı bir araştırmada okul hemşirelernin öğrencilerin sağlığını geliştirmek ve diğer okul sağlığı programlarının planlanmasında lider oldukları sonucu elde edilmiştir (34). Araştırmalar translasyonel araştırma modelinin T0 ve T1 aşamaları ile okul sağlığı alanına adaptasyon sağlayabilmektedir $(36,37)$.

Ülkemizde okul hemşireliği alanında T3 - T4 aşamasında olan translasyonel araştırmalar uygulanamamakta, bu tür projeler yaşama geçirilememektedir. Natinal Association of School Nursing (NASN)'e göre kanıta dayalı uygulama ve araştırma okul hemşireliğinin profesyonel standartlarından biridir. Bu standartların hayata geçirilmesi için NASN tarafından bir dizi yeterlilikler tanımlanmıştır. Bu yeterlilikleri; araştırma bulgularıyla birlikte, kanıta dayalı hemşirelik bilgi birikimini kullanma, araştırma aktivitelerinde konumuna ve eğitim seviyesine uygun olarak etkin rol alma, yeni kanıtları ekleyerek okul hemşireliği uygulamalarını güncelleme, veri toplama, özel klinik problemleri belirleme, araştırmaların analiz ve yorumlanmasında görev alma olarak belirtilmiştir $(25,38)$.

Translasyonel araştırmaların eksikliğine bağlı olarak da okul hemşirelerinin kanıtlardan yeterince faydalanamadığı görülmektedir (14). Klinik karar verme sürecinde kanıtların kullanılamaması sonucu tam anlamıyla maliyet yarar analizi yapılamamaktadır (7). Oysa Translasyonel araştırma sonuçlarının okul sağlığı uygulamalarında kullanılması öğrencilerin sağlı̆̆ını korur, gelişimini destekler ve akademik başarısını arttırarak araştırma ile uygulama arasındaki boşluğu giderir (18, 22).

Okul hemşirelerinin translasyonel araştırmalara liderlik ederek ve kanıt kullanımı konusunda profesyonel davranarak katkı sağlaması beklenir (27). Mevcut kanıtların kullanımı, translasyonel araştırmalara gönüllülük ve çocuk haklarının korunması okul hemşirelerinin primer görevleri arasındadır. Okul sağlığı hizmetlerine erişim, kalite, güvenlik, verimlilik ve etkililik ile ilgili temel problemler raporlarla açıklanmıştır. Bu problemlerin çözümüne yönelik yeni araştırma stratejilerinin tanımlanabilmesi için teknoloji ve bilişimden yararlanılabileceği ifade edilmiştir (11).

\section{Sonuç ve Öneriler}

Translasyonel araştırma son yıllarda tıp ve hemşirelik literatüründe sıklıkla yer alan bir kavramdır. Hemşirelik araştırmalarında translasyonel araştırma kullanımı bakımın kalitesini artıracak ve bakımda standardizasyonu sağlayarak ortak bir dil oluşumunu destekleyecektir. Hemşirelik uygulamalarının kanıt temelli olması klinik uygulamalarda fark yaratmak için önem arz etmektedir. Sağlık bakım ekibinin vazgeçilmez birer üyesi olan hemşireler transdisipliner ilişki geliştirmede önemli görevler üstlenmektedir. Çünkü hemşirelik kliniklerde tüm disiplinlerle ayrı ayrı iletişim kuran ve en çok iş birliği geliştiren meslek grubu olarak tanımlanmaktadır. Bu bağlamda hemşirelerin güncel ve konuyla ilgili literatüre erişimleri sağlanmalıdır. Hemşirelik bilimde TA'ların istenilen düzeyde yapılmadığı göze çarpmaktadır. Ancak hemşirelik TA alanında liderler yetiştirmeye başlamıştır. Bu bağlamda hemşirelik mesleğinde TA için gerekli eğitimleri veren araştırmacılara ve transdipliner ilişki geliştirecek yeni liderlere gereksinim duyulmaktadır.

Okul hemşireliğinde elektronik sağlık kayıtları; iş akış, tasarım, dökümantasyon, düzenleme özelliği ile hemşire memnuniyeti araştırmalarının odak noktası olmuştur. Bu alanda translasyonel araştırmalardan tam ve doğru sonuç elde edilebilmesi için elektronik sağlık kayıtlarının standartlaşmış hemşirelik verileri içerisine entegrasyonu şarttır.

Bilimin sürekli gelişen ve değişen doğasına uyum sağlamak, transdisipliner ilişkilerin güçlendirilmesi, evde, okulda, iş yerinde sağlık bakım uygulamalarının yaygınlaştırılması ve profesyonel düzeyde sunulması, araştırmalar ile elde edilmiş kanıtların sistematize edilerek uygulama bilgisine dönüştürülmesi TA'ları destekleyici adımlardır.

Translasyonel araştırma kavramının hemşireler tarafından farkedilmesi, kanıt temelli girişimlerin uygulama alanlarına taşınması, yeni bilgilerin sistematize edilmesi, deneysel araştırmaların arttırılması sağlık bakımının güvenirliğini, etkililiğini, görünürlüğünü artıracak uygulamalardır. Sağlık bakım ekibinin profesyonel üyeleri olan hemşirelerin eleştirel düşünmesi, gelişmemiş yönlerini fark edebilmesi için iç görülü davranması sorunların saptanmasına ve gelişime odaklanmaya olanak tanır. Lider hemşirelerin en önemli görevleri transdisipliner ilişkileri desteklemek, TA araştırma projelerinin ve bilimsel bilgilerin sistematize edilmesinde aktif rol üstlenmektir.

\section{Bilgilendirme}

Yazarların tümü çalışmanın tamamına katkı sağlamış ve son halini onaylamıştır. Derleme yazımı ile ilgili herhangi bir kurum ya da kuruluştan destek alınmamıştır. Bu derleme araştırma ve bilimsel yayın etiğine uyularak yazılmıştır. Araştırmacılar arasında herhangi bir çıkar çatışması bulunmamaktadır.

\section{Kaynaklar}

1. Christensen M. Craft J. The nursing professional unit: translating acute and criticalcare nursing research. International Practice Development Journal 2017;7(2).

2. Mitchel S. Fisher C. Hastings C. Silverman. L. Wallen G. A thematic analysis of theoretical models for translational science in nursing: Mapping the field. Nursing Outlook 2010; 58:287-300.

3. Wendler M. Kirkbride G. Wade K. Ferrell L. Translational research: a concept analysis. Research and Theory for Nursing Practice 2013; 27(3): 214-232.

4. Bell E. Harpur S. Doherty K. Struber J. Davies L. What is translational research? Background, concepts and definition. International Public Health Journal 2011;3(2):133-143.

5. Rubio D. Schoenbaum E. Lee L. Schteingart D. Marantz P. Anderson K. Platt L et al. Defining translational research: implications for training. Academic Medicine 2010;85(3): 470-475. 
Derleme

6. Lean M. Mann J. Elliott R. Schofiled G. Translational research. British Medical Journal 2008;337(7672):705-706.

7. Woods N. F. Magyary D. L. Translational research: Why nursing's interdisciplinary collaboration is essential. Res Theory Nurs Pract 2010; 24(1):9-24.

8. Manley K. Mc Cormack B. Purpose, methodology, facilitation and evaluation. Nursing in Critical Care 2008;(19. 22-29. doi:10.1046/j.1478-5153.2003.00003.x.

9. Titler M. G. Everett L. Q. Adams S. Implications for implementation science. Nursing Research 2007; 56(4):53-S59.

10. Cowell J. M. Translational Science for School Nursing and School Health Services: Implications for Authors 2016.

11. Westra B. L. Latimer G. E. Matney S. A. Park J. I. Sensmeier J. Simpson R. L et al. A national action plan for sharable and comparable nursing data to support practice and translational research for transforming healthcare. Journal of the American Medical Informatics Association 2015; 22(3): 600-607.

12. Hill NL. Penrod J. Milone-Nuzzo P. Merging person-centered care with translational research to improvethe lives of older adults: creating community-based nursing research networks. Journal of gerontological nursing 2014;40(10): 66-74.

13. Green L.W. Ottoson J.M. Garcia C. Hiatt R.A. Diffusion theory and knowledge dissemination, utilization, and integration in public health. Annua 1Review of Public Health 2009; 30: 151-174. doi: 10.1146/annurev.publhealth.031308.100049

14. Grady P.A. Translational research and nursing science. Nursing Outlook 2010; 58:164- 166. doi: 10.1016/j.outlook.2010.01.001

15. Westfall J. Mold J. Fagnan L. Practice-based research "bluehighways" on the NIH roadmap. Journal of the American Medical Association 2007; 297(4): 403-406.

16. Chesla CA. Translational research: Essential contributions from interpretive nursing science. Research in Nursing and Health 2008; 31: 381-390.

17. Jones K. R. Fink R. Vojir C. Pepper G. Hutt E. Clark L. Me llis, B. K. Translation research in long-term care: Improving pain management in nursing homes. Worldviews on Evidence-Based Nursing 2004; 1, S13-S20.

18. Şendir M. Yaman R. Kızıl H. Özdemir C. Kubat G. Hemşirelik kanıtlarının uygulamaya dönüştüğü bilim: Translasyonel hemşirelik. Journal of Human Sciences 2019; 16(1), 126-133. doi:10.14687/jhs.v16i1.5440.

19. Aiken L. Clarke S. P. Cheung R. B. Sloane D. M. Silber J. H. Education levels of hospital nurses and patient mortality. Journal of the American Medical Association 2003; 290:1617-1623.

20. Aiken L. Clarke S. P. Sloane D. M. Sochalski J. Silber J.H. Hospital nurses taffing and patient mortality, nurse burnout, and job dissatisfaction. Journal of the American Medical Association 2002; 288: 215-222.

21. Wang Y.L. Volker DL. Caring for Students With Type 1 Diabetes: School Nurses' Experiences. J Sch Nurs 2013; 29(1): 31-38.

22. Ayaz S. İlköğretim Öğretmenlerinin Okul Sağlı̆̆ı Hemşireliğine İlişkin Görüşleri. Hacettepe Üniversitesi Hemşirelik Fakültesi Dergisi 2014; 42-52.

23. Altuntaş S, Baykal Ü. Okul hemşirelerinin iş, iş ortamı, rol ve sorumluluklarına yönelik görüşleri. Hemşirelikte Eğitim ve Araştırma Dergisi 2012; 9 (1): 43-50.

24. Pianalto A. M. Wall M. C. The effect of school based nursing on health related outcomes in children: A review of literature 2016

25. National Association of School Nurses. Framework for 21st century school nursing practice: National Association of School Nurses. NASN School Nurse 2016; 31(1): 45-53.

26. Barnes, Lisa M., (2012). "Evidence Based Practice in School Nursing: A Study of School Nurses in Central and Eastern North Carolina"Nursing Theses and Capstone Projects. https://digitalcommons.gardner-webb.edu/nursing etd/98

27. Pearson A. Jordan Z. Munn Z. Translational science and evidence-based health: A clarification. Nursing Research and Practice 2012;1-6.

28. Johnson K. H. Bergren, M. D. Meaningful use of school health data. The Journal of School Nursing 2011; 27, $102-110$. doi: $10.1177 / 1059840510391267$.

29. Ulutaşdemir N. Balsak H. Öztürk Çopur E. Demiroğlu N. Halk Sağlığı Hemşireliğinin Bir Dalı: Okul Sağlığı Hemşireliğgi. Turkiye Klinikleri J Public Health Nurs-Special Topics 2016;2(1):121-124.

30. Bagby K. Adams S. Evidence-Based Practice Fuideline: Increasing Physical Activity in Schools-Kindergarten Through 8th Grade, The Journal of School Nursing 2007;23(3).

31. Adams S. McCarthy M.A. Evidence-Based Practice and School Nursing 2005; 21(5):258-265.

32. Reeves, P. Deeming S. Ramanathan, S. Wiggers, J. Wolfenden, L. Searles, A. Measurement of the translation and impact from a childhood obesity trial programme: rationale and protocol for a research impact assessment. Health research policy and systems 2017; 15(1), 111.

33. McClune A. J. Conway, A. Farm Safety: A Tale of Translational Research and Collaboration. Pediatric nursing 2016; 42(1).

34. American Nurses Association (ANA). Nursing: Scope and standards of practice (2nd ed.). Silver Spring 2010; MD: Author.

35. Baldwin J. A. Williamson H. J. Eaves E. R. Levin B. L. Burton D. L. Massey O. T. Broadening measures of success: results of a behavioral health translational research training program. Implementation Science 2017; $12(1), 92$.

36. Trivellini G. Doveri C. Mastorci F. Bastiani L. Cappa C. Vassalle C. Pingitore A. Innovative web-based tool for promoting well-being among healthy adolescents: An implementation protocol. Journal of Translational Science 2018; 5(3): 2-5. doi: 10.15761/JTS.100026. 
Derleme

37. Chabot G. Godin G. Marie-Pierre Gagnon M. Determinants of the intention of elementary school nurses to adopt a redefined role in health promotion at school. Implementation Science 2010; 5:93:3-10.

38. Özalp A.M. Duymuş S.E. Dost A. Evidence-based approach in school health nursıng. Internatıonal Student Congress; 2627 Mart 2019; İstanbul 